\title{
Educational Alienation in Contemporary Culture: Addressing Challenges to Students' Socialization into the Major
}

\author{
Ray Muller and S. Hooshang Pazaki ${ }^{1}$ \\ "At first when I found out I had to take sociology as a \\ major ...I was angered because ...I was told by my peers \\ that [sociology] was not only common sense, but a ma- \\ jor that disregarded academic integrity and was merely \\ an easy ride through college."
}

Anonymous Sociology Major

In response to a lack of adequate socialization of sociology students into the major, our department developed and recently instituted a new course entitled Sociological Inquiry. In our experience, many of our majors do not have a genuine interest and understanding of sociology and the sociological perspective. Our limited experience in teaching Sociological Inquiry does, however, point to some initial success in helping students develop a deeper appreciation for the discipline. We begin the paper with a brief sketch of the major cultural and structural trends contributing to the curricular and pedagogical challenges we encounter. We also propose a typology of educational alienation as a heuristic tool with which to explore these challenges and to discuss the rationale for developing Sociological Inquiry. In closing, we explore the limitations of the course as it is currently taught and consider how one might best address these limitations in the semesters to come. [Article copies available for a fee from The Transformative Studies Institute. E-mail address: journal@transformativestudies.org Website: http://www.transformativestudies.org @2011 by The Transformative Studies Institute. All rights reserved.]

KEYWORDS: Educational Alienation, Consumerist Ideology, Socializing Students, Public Sociology, Critical Pedagogy.

\footnotetext{
${ }^{1}$ The names of the authors appear alphabetical order.

Ray Muller, Ph.D., Associate Professor of Sociology, East Stroudsburg University of Pennsylvania.

S. Hooshang Pazaki, Ph.D., is Associate Professor of Sociology, East Stroudsburg University of Pennsylvania. Address correspondence to: S. Hooshang Pazaki, East Stroudsburg University, 200 Prospect Street, East Stroudsburg, Pennsylvania 18301; e-mail: shpazaki@po-box.esu.edu.
} 